\title{
ECONOMÍA E INSTITUCIONES EN EL PENSAMIENTO DE ANTONIO ROSMINI: COINCIDENCIAS Y DIFERENCIAS CON LA TRADICIÓN LIBERAL
}

\author{
CARLOS HOEVEL*
}

Antonio Rosmini (1797-1855), verdadero gigante del pensamiento, permaneció incomprensible y asombrosamente oculto para el lector general durante casi un siglo y medio. La obra del «roveretano» - como se llama a Rosmini por su nacimiento en Rovereto, al norte de Italia- sufrió el conflicto del penoso parto de la modernidad dentro del seno de la Iglesia y la cultura católicas del siglo XIX. Sus casi cien tomos — que van desde la Metafísica hasta la Economía pasando por la Antropología, la Ética, el Derecho y la Políticafueron objeto de numerosos estudios predominantemente italianos, durante la segunda mitad del siglo XIX y todo el siglo XX. Así, su obra está comenzado a ser realmente descubierta para el mundo entero en este principio del siglo XXI.

Pero, ¿por qué traemos a colación a este filósofo católico en relación al tema de economía e instituciones? En primer lugar, porque, a diferencia de muchos católicos de la era moderna, Rosmini no compartió un ideal medieval-corporativo de la sociedad ni rechazó todos los cambios introducidos por la modernidad, especialmente el papel cada vez más importante de la economía, del mercado y de la nueva ciencia de la economía política. En efecto, Rosmini fue un pensador católico sui generis que no podría de ningún modo ser clasificado entre quienes consideraban despectivamente estos resultados de la modernidad como meros

\footnotetext{
* Carlos Hoevel es Licenciado en Filosofía (UCA) y M.A. in the Social Sciences (University of Chicago). Doctorando en Filosofía sobre el tema «La filosofía de la economía en el pensamiento de Antonio Rosmini». Director de la Revista Valores en la sociedad industrial.
} 
productos de una mentalidad burguesa o utilitarista. Si bien respetó y amó la tradición, no compartió la visión de los católicos tradicionalistas que sostenían la oposición esencial entre las realidades económicas y el ideal religioso de la vida. Pero tampoco podría ser ubicado entre los católicos «sociales» que siempre vieron al mercado como enemigo irreconciliable de la justicia social y de la caridad cristiana. Rosmini fue uno de los primeros grandes pensadores católicos que, en pleno lanzamiento de la era industrial y de la nueva economía política, y después de los casi dos siglos transcurridos desde el último gran proyecto de ética económica cristiana de la escolástica española, encaró un proyecto de síntesis e integración entre las esferas de la economía, la ética y la religión en perspectiva moderna.

Por lo demás, siendo fundamentalmente filósofo, Rosmini se interesó, sin embargo, y conoció en profundidad el pensamiento económico naciente de su época. Estudió economía en los textos de los mercantilistas y los fisiócratas pero sobre todo en las obras de Adam Smith, Thomas Malthus, Jean-Baptiste Say, Simonde de Sismondi y los italianos Antonio Genovesi, Melchiore Gioia y Giandomenico Romagnosi, entre muchos otros. Uno de sus objetivos principales fue siempre el de integrar críticamente su monumental obra filosófica, política y jurídica con el cuerpo de la economía conocido hasta entonces.

En este contexto, encaró dos objetivos. Por un lado realizar una indagación profunda sobre la acción económica en el contexto de la acción humana, es decir, quiso comprender el último fundamento antropológico de las relaciones entre la economía y la ética. Pero además, trató de entender la economía en el marco de las instituciones sociales. En efecto, Rosmini buscó alcanzar este segundo objetivo, que es el que nos interesa enfatizar aquí, en medio del intenso debate social y político de la Italia de su tiempo que pasaba del antiguo régimen de monarquías absolutas a un tipo de organización social constitucional y liberal. Así, una de sus principales preocupaciones fue la de estudiar cómo se habría de enmarcar la economía dentro del nuevo orden jurídico y político. En esta tarea, Rosmini participó en un intenso debate sobre Diritto e Economia desarrollado especialmente en diálogo con el economista civil Giandomenico Romagnosi, que fue una 
especie de versión italiana decimonónica de nuestro contemporáneo debate sobre «Law and Economics». Pero la postura de Rosmini en este tema trasciende a Italia y requiere ser entendida dentro del marco más amplio de la discusión sobre economía e instituciones de fines del siglo XVIII y principios del siglo XIX que ocurre fundamentalmente en Gran Bretaña y Francia. Pero, ¿dónde se ubica Rosmini si lo entendemos según las coordenadas de aquella discusión mayor?

En general, se puede decir que Rosmini no está ciertamente del lado del racionalismo e iluminismo franceses en cuanto ideología de base del estatismo y del utopismo social. Por el contrario, una de las tareas mayores del roveretano fue su crítica permanente no sólo a los excesos de la revolución francesa sino también a los proyectos constructivistas del socialismo utópico y del comunismo. Dentro de su obra son fundamentales sus Ensayos sobre el socialismo y el comunismo en los que critica duramente las concepciones tecnocráticas de pensadores como Saint-Simon, Owen y Fourier. Lo mismo se puede decir de su crítica a la estatolatría — tal como él la llama- de Rousseau y de Hegel. Un capítulo especial tiene también en su obra la crítica a la versión inglesa del racionalismo social por antonomasia que él ve encarnada en la obra de Jeremy Bentham. ¡Cuántas páginas dedica Rosmini a desmantelar, pieza por pieza, el proyecto de convertir a la sociedad en un gran panopticon!

Entonces, dado que Rosmini es claramente un crítico del estatismo y del socialismo - y tomando en cuenta que está bien lejos de ser un corporativista- ¿podemos deducir de ello que su concepción de la economía en relación con las instituciones sigue la tradición de la corriente contraria, es decir, de la gran tradición del liberalismo económico representada en su tiempo especialmente por el iluminismo escocés o, en todo caso, por el viejo wighismo inglés? La respuesta, a primera vista, parecería ser sencillamente afirmativa. De hecho existen algunas interpretaciones ya clásicas sobre el pensamiento económico e institucional del roveretano que lo ubican decididamente en la línea del liberalismo inglés. ${ }^{1}$

1 Cfr. Especialmente Pietro Piovani, La teodicea sociale di Rosmini, CEDAM, Padova 1957. 
Sin embargo, si se observa más de cerca, la obra de Rosmini presenta ciertamente coincidencias asombrosas con esta tradición pero también, por lo demás, llamativas diferencias. Es precisamente el análisis de algunas de estas coincidencias y diferencias con la tradición liberal anglosajona donde probablemente se encuentra la mayor originalidad y fuerza de la concepción de Rosmini en torno a la relación entre economía e instituciones, de donde pueden extraerse, por otra parte, algunas ideas iluminadoras para nuestro propio debate contemporáneo sobre el tema. Es por eso que intentaremos presentarlas de manera sucinta en las líneas que siguen para luego esbozar nuestra propia conclusión.

\section{I \\ LAS COINCIDENCIAS}

\section{La importancia del factor económico}

La concepción sobre las relaciones entre la economía y las instituciones políticas y jurídicas tiene en Rosmini importantes coincidencias con las del iluminismo escocés - Hume, Smith, Roberston, Young-que conoce muy bien y también con la tradición del viejo whigismo inglés encarnado por ejemplo en Burke y contemporáneamente en el pensamiento de Hayek. El roveretano aprecia la idea de que la formación de las instituciones políticas y jurídicas se explica en buena parte como resultado de una lenta evolución histórica que va dejando como sedimento normas e instituciones que son más fruto de la tradición y de la experiencia que de la razón abstracta. Pero quizás lo que más llama la atención, es el peso enorme que da Rosmini a los intereses económicos en la formación histórica de estas instituciones. De hecho, Rosmini - en una vena muy burkeana- llama a este proceso «constitución natural de la sociedad civil» por el que se explica la formación de las sociedades civiles o políticas modernas en gran medida como la consecuencia natural del despliegue de las fuerzas económicas que influyen y condicionan su organización. 
En efecto, en su obra Della naturale costituzione della società civile, ${ }^{2}$ Rosmini describe el paso de una sociedad «familiar» con una economía sin mercados, cerrada y de subsistencia, basada en la fuerza de la influencia personal, a una sociedad «civil» o política con economía de mercado, abierta y de consumos y producción sofisticados en donde la clave es el derecho de propiedad. Rosmini se remonta a la época romana para mostrar este pasaje de la sociedad familiar a la sociedad civil y la importancia crucial del factor económico en dicho pasaje. Así, señala el paso de la división del pueblo romano realizada originalmente por Rómulo, de acuerdo a una concepción familiar de la sociedad basada en la fuerza guerrera de las personas, ${ }^{3}$ a la de Servio Tullio quien, en cambio «distribuyó en seis clases a todo el pueblo romano según los grados de la riqueza». ${ }^{4}$ Por lo demás, ésta última fue, para Rosmini «la más sabia institución que tuvieron los romanos» $\mathrm{y}$ «el núcleo de la política romana». ${ }^{5}$ Y esto no por razones ideológicas sino por lo que Rosmini considera una razón absolutamente fáctica que se desprende de la naturaleza de las cosas y no de una teoría abstracta. ${ }^{6}$ Esta razón fáctica radicaría en el hecho de que el crecimiento de una sociedad en extensión y número de miembros, implica siempre necesariamente una multiplicación de la propiedad, división del trabajo, mayor creación de riqueza, sofisticación e intensificación de necesidades y la creación de una inevitable desigualdad de resultados para los diferentes individuos implicados en todo este proceso. ${ }^{7}$

Así, la consecuencia natural es que el orden político y jurídico de la sociedad civil deba necesariamente reflejar esta realidad

\footnotetext{
${ }^{2}$ Della naturale costituzione della società civile, Filosofia della politica, Rovereto, Tip. Giorgio Grigoletti, 1887.

3 «La division che fee Romolo del popolo romano fu un'istituzione famigliare; poichè essa ebbe riguardo alle persone, o sia alla forza militare, e non alle ricchezze.» Della naturale costituzione della società civile, ibid., p. 207.

4 Ibid., p. 210.

5 Ibid., p. 212.

6 «Il peso che ha la ricchezza nell' Amministrazione sociale è un fatto independente dagli ingegni degli uomini.» Ibid., p. 213.

7 «[...]bisognava dar tempo perchè le terre si divissero, perchè le famiglie parte assai moltiplicate, parte poco o nulla, od estinte, e gli altri accidenti producessero una notabile diseguaglianza fra i proprietarî...» Ibid., p. 213.
} 
y para hacerlo deba también, por tanto, ser distinto al que rige las sociedades «familiares». Ignorar estas fuerzas o intentar eliminarlas del escenario de la sociedad a través de un orden jurídico y político artificialmente impuesto es, para Rosmini, ir en contra de las leyes profundas de evolución histórica de la sociedad civil ya que «la naturaleza de las cosas ha indicado a los pueblos la ley mostrada por nosotros: que la administración social sea distribuida en proporción a la riqueza.» 8

Por otra parte, el roveretano ve repetirse este mismo proceso en el origen de la sociedad civil o política moderna que él remonta al surgimiento medieval de las comunas burguesas ${ }^{9}$ que fueron en gran medida la expresión civil y social de una nueva realidad económica basada en el dinero, en una economía monetaria y en su protección jurídica en base al derecho de propiedad. ${ }^{10}$ Frente a esta realidad, Rosmini menciona la tendencia siempre presente - como peso muerto de las sociedades civiles- a la «falta de economía», esto es, al desprecio del factor económico en el gobierno de la sociedad. Este desprecio sería un residuo feudal por el que se consideraría a la riqueza como un recurso que se obtiene por la fuerza y la expoliación y no por el trabajo productivo y se la distribuye no en base a la productividad y al esfuerzo individuales, sino en base al arbitrio y la generosidad de un señor. ${ }^{11}$ Rosmini ve allí el origen de la mentalidad providencialista y

8 Ibid., p. 213.

9 Cfr. Ibid., pp. 229 ss.

10 «La società civile non può esistere se non mediante il danaro: ella paga gl'impiegati e la milizia, come abbiam detto, fa eseguire opere pubbliche, ecc; nulla fa senza danaro.» La costituzione secondo la giustizia sociale, Progetti di costituzione, Saggi editi e inediti sullo stato, a cura di Carlo Gray, Opere edite e inedite, vol. XXIV, Fratelli Bocca Editori, Milano, 1952, p. 198. «Il danaro nella società sviluppata è il rappresentante di tutto: nella società non sviluppata nè venuta a civiltà è ancora la proprietà quella condizione a cui l'uomo può vivere, educarsi, operare.» Ibid., p. 197.

11 «Il che però più impetuosamente e anche disordinadamente avviene in quella gente che si fa ricca col vigile e faticoso amore dell'acquistare, ma a cui toccò una ricchezza non principalmente desiderata siccome una schiava venuta dietro alla potenza e alla fortuna. Non cercavano i romani l'oro: volevano solo la signoria dei signori dell'oro: non cercavano gli Spagnuoli le miniere americane, ma da prima la novità di un altro mondo. Però non avendo costoro, come fu già molte fiaro presservato, il cuore apposto alla ricchezza, e questa essendo tuttavia in sequela della potenza venuta lor nelle mani incontanente grandissima non seppero nè pregiarla, nè 
moralista del gobierno de la sociedad y cree que inevitablemente deberá ser reemplazada por una concepción administrativoeconómica del mismo. ${ }^{12}$

\section{El papel del orden espontáneo}

Rosmini también coincide con la tradición liberal anglosajona en la importancia del papel del orden espontáneo surgido del entramado de acciones individuales en la formación tanto del orden económico como de las instituciones jurídicas y políticas. En este sentido para el roveretano juega un importante papel el conocimiento instintivo de los propios intereses que tiene cada individuo el cual produce beneficios sociales o colectivos no intencionales. Así, Rosmini sostiene que los pueblos pueden actuar «guiados por una razón práctica, un instinto social...no se puede determinar las razones precisas que llevan a la gente a actuar socialmente...De hecho aunque la gente pueda tener como motivo de su acción su interés inmediato y presente... sin embargo este obrar puede conllevar óptimos efectos lejanos y universales pero no porque hayan sido previstos o calculados por la gente sino porque la naturaleza misma la condujo a actuar de tal modo que el bien presente individual buscado por ellos resulta per accidens el bien mismo de toda la sociedad...»13

De allí que Rosmini considere un absurdo imposible el pretender reemplazar este orden por una planificación calculada por uno o más individuos. En efecto, para él esto sería comparar a la mente del hombre con la mente divina de modo que pudiera

usarla, nè conservarla: nè altro pesniero s' ebbero che di profonderla e gittarla. Quelli all'opposto che acquiserano tali cose colle industrie e coi commerci, poniamo gli inglesi, hanno pur colle lunghe cure e sollecitudini nutricato in sè stessi l'effetto dell'oro e però nol gittano sì agevolmente. Dall'abondanza dunque della pecunia che sovverchia le necessità e dalla disposizione dei ricchi popoli riguardo alle industrie ed ai calcoli dei guadagni, si fa ragione a quello che dispone la nazione di porre nei suoi piaceri.» Opere inedite di politica. A cura del Prof. G.B. Nicola, Milano, Stab. Tipo. Lit. G. Tenconi, 1923, pp. 176-177.

12 Della naturale Costituzione della società civile, edic. cit, p. 263.

${ }^{13}$ La società ed il suo fine, Filosofia della Politica. A cura di Sergio Cotta, Milano, Rusconi, 1985, pp. 112-114. 
prever todas las posibles consecuencias posibles, directas e indirectas, derivadas de las acciones interrelacionadas de millones de individuos. Así, el principio de planificación utilitaria y consecuencialista como único principio de la organización social lleva al absurdo de que las probabilidades de obtener un resultado final positivo o negativo son igualmente infinitas, lo cual convierte a la planificación en una acción esencialmente irracional: «¿Dónde están los límites del sistema de la utilidad?» — se pregunta el roveretano. «No tiene ninguno. Su acción es infinita como una voluntad arbitraria: supone que se puede hacer una reforma tras otra en la sociedad hasta el infinito: pero no se sabrá jamás con certeza si se ha progresado o se ha retrocedido.» ${ }^{14}$ De allí que, por lo demás, Rosmini enfatice la gran importancia de la libertad para la sociedad y para la economía como principio general y que para él la idea de que el gobierno se haga cargo de manera permanente del bienestar de los individuos de acuerdo a necesidades determinables de manera supuestamente objetiva por un planificador o ingeniero social representen la muerte de la economía y de la sociedad.

\section{La regulación jurídica y ética}

Otra coincidencia de Rosmini con la tradición liberal anglosajona es que la regulación de los intereses espontáneos de la sociedad y de la economía debe ser mayormente jurídica y no política. El mejor medio para hacer florecer a la sociedad es dar el mayor grado de libertad posible en el marco de normas amplias que eviten al máximo toda discrecionalidad gubernamental. Rosmini considera que el control político de la economía es en general distorsivo de los incentivos que requieren los intereses económicos. «El gobierno se pone en peligro de perturbar el orden legítimo de la riqueza si presume de poder darle dirección», de modo que lo mejor que le cabe hacer es propender a «acrecentar el movimiento y la actividad de los ciudadanos en general», esto es

14 Della naturale Costituzione della società civile, edic. cit. p. 151. 
«...no tanto en este o aquel ramo de la economía sino en todos los ramos, promoviendo no esta o aquella industria particular sino la actividad y la industria en general». ${ }^{15}$ De hecho el intento de dirigir la economía exclusivamente mediante una política discrecional de subsidios y protecciones especiales es casi siempre distorsivo y contraproducente. ${ }^{16} \mathrm{El}$ Estado tiene que apoyarse sobre todo en el fortalecimiento de las instituciones jurídico-económicas del derecho de propiedad y la previsibilidad de los contratos que den un marco seguro para el desarrollo económico.

En ese sentido, para Rosmini el derecho tiene un papel central para el crecimiento y la evolución sana de una economía. El roveretano pone gran énfasis en la íntima relación que existe entre la calidad jurídica de la legislación de una sociedad y las posibilidades de generación de utilidad económica de la misma. De hecho, uno de los problemas más graves de la legislación moderna es para él su carácter abstracto y excesivamente generalista, que surge de no haber sido elaborada tomando en cuenta la experiencia de los hechos. «Este siglo abrazó como cierto - dice Rosmini- el principio de que toda mejora consiste en generalizar las cosas.» ${ }^{17} \mathrm{Y}$ así «el vicio de la generalidad moderna consiste en sacrificar los particulares contra aquello que exige la naturaleza, la cual quiere más bien que sobre los particulares nosotros fundemos lo general.»18

Como consecuencia, el abstractismo legislativo pone impedimentos innecesarios a posibilidades de crecimiento económico que se darían si no se intentaran resolver a priori los conflictos entre intereses que muchas veces pueden ser resueltos por iniciativa o acuerdo de los individuos involucrados que conocen mejor

15 Opere inedite di politica, edic. cit., p. 138.

16 «Io credo collo Smith e con altri economisti che la piú utile distribuzione della ricchezza si faccia dalla stessa natura delle cose, e tanto è più perfetta questa distribuzione e direzione di ricchezza quanto è più vasto il luogo ed il tempo in cui essa si considera» ibid., pp. 136-137. Cfr. Adam Smith, An Inquiry into the Nature and Causes of The Wealth of Nations, I, University of Chicago Press, 1990, p. 475: «it is by no means certain that this artificial direction is likely to be more advantageous to the society than that into which it would have gone of its own accord.»

17 Opere inedite di politica, edic. cit., p. 75.

18 Ibid., pp. 76-77. 
que nadie las condiciones de una situación particular. En efecto, «los gobiernos - agrega nuestro autor- proceden con disposiciones generales y en casi todos los casos no puede hacerlo de otra manera. Pero por esta razón precisamente pueden errar fácilmente. Cuando un gobierno promulga una ley o un decreto cree que sólo tiene que considerar sus efectos generales, sin descender a las anomalías de los individuos particulares. La ley es considerada en abstracto. Pero esto no es suficiente. De hecho, a menudo derechos individuales son sacrificados injustamente bajo la inexorable generalidad de la ley... Así, frecuentemente los gobiernos desperdician mediante estas disposiciones recursos económicos que en rigor pertenecen a los individuos...»19

De este modo, en opinión de Rosmini, la verdadera justicia distributiva en materia económica no se logra mediante una legislación racionalista que establezca a priori cómo deben resultar las cosas. Por el contrario, toda buena legislación debe tener una puerta abierta para la expresión de las posibilidades contenidas en la realidad concreta en la que actúan los individuos particulares. «Por ello, cuanto más se observa lo particular, tanto más nos acercamos a la justicia distributiva.» ${ }^{20}$

Así, Rosmini se opone al legalismo económico que pretende prever y controlar todos los conflictos por la vía de una legislación omnicomprensiva acompañada de coacción judicial. Por el contrario, el roveretano es un crítico del legalismo estatista de estilo francés apoyándose mucho para ello en el pensamiento jurídico inglés y escocés de inspiración histórica de Hume, Blackstone, Robertson, Young y en muchos aspectos de la Constitución inglesa. En efecto, para Rosmini el racionalismo jurídico francés suele ser producto de «la improvisación de mentes audaces e imaginativas, demasiado infatuadas por teorías extremadamente generales e imperfectas...hijas de una filosofía que quiere romper con el pasado» ${ }^{21}$ y que suele estar, por tanto, lleno de «vanas abstracciones» y de «teorías inaplicables a la realidad social.» ${ }^{22}$

\footnotetext{
19 La società ed il suo fine, edic. cit., L. II, C. XII.

20 Opere inedite di politica, edic. cit., pp. 68-69.

21 La costituzione secondo la giustizia sociale, edic. cit., capítulo I.

22 Ibid., cap. III.
} 
Por el contrario, considera que la tradición jurídica británica ha sido «formada paso a paso, sin un esquema premeditado, constantemente corregida y enmendada en acuerdo con las diversas fuerzas sociales contrapuestas y con la urgencia de los instintos y de las necesidades de la gente.» ${ }^{23}$ Por lo demás, al igual que para Burke, Smith o Hayek, Rosmini cree que aún la legislación concebida de este último modo no debe pretender abarcarlo todo $\mathrm{y}$ que hay que dejar un amplio espacio abierto al papel de la ética de los individuos como instrumento para una resolución justa en los conflictos de intereses: "sólo la ética puede enseñar la buena fe y la moderación en el ejercicio del propio derecho.» ${ }^{24}$

II

\section{LAS DIFERENCIAS}

\section{La falibilidad del orden espontáneo y sus consecuencias en la política económica}

Rosmini sustenta así la idea de una economía basada fundamentalmente en la libertad en el marco de instituciones jurídicas. Sin embargo, las coincidencias con la tradición anglosajona no pueden ocultar sus profundas diferencias. En mi opinión, Rosmini parte de un planteamiento ético y antropológico diferente del de esta tradición que va a tener importantes consecuencias en el modo de entender los puntos mencionados, incluso cuando son a primera vista coincidentes.

Un primer punto fundamental de las diferencias entre Rosmini y la tradición liberal anglosajona estaría en su interpretación del orden espontáneo. Si bien, como señalábamos antes, el roveretano valora mucho el papel de la interrelación espontánea de los individuos que siguen su propio interés en la sociedad, no cree que este orden espontáneo sea siempre infalible. Por el contrario,

${ }^{23}$ Ibid., cap. I.

24 Society and its Purpose, vol. 2 of The Philosophy of Politics, traducido por Denis Cleary y Terence Watson, Rosmini House, Durham, U.K., from La societa ed il suo fine, 1994, n. 144. 
Rosmini considera que el orden espontáneo varía en su eficacia para producir resultados socialmente positivos dependiendo del tiempo y el lugar en que se manifieste.

En efecto, en primer lugar, está el factor histórico: el orden espontáneo de los intereses individuales no tiene la misma eficacia en todas las épocas. Aquí entramos en la filosofía de la historia de Rosmini. En tal sentido, hay épocas en que el orden espontáneo de los individuos coincide con el bien de la sociedad: se trata de las épocas fundacionales de las sociedades donde en general los intereses de los individuos son altruistas y coinciden con los de la sociedad. En efecto, «la infancia de una sociedad es siempre una época eminentemente patriótica. El bien de cada persona, considerada como miembro de la unidad social, es equivalente al bien elemental de la sociedad misma.» ${ }^{25}$ Esto se debe al hecho de que cuando una sociedad está en sus comienzos, sus miembros son muy conscientes de que su propia supervivencia depende de la supervivencia de la sociedad. Así «en el principio la existencia misma de la sociedad es el bien que todos sus miembros perciben inmediata y vívidamente.» ${ }^{26}$ Por esta razón en esos tiempos, coincidiendo el interés de la supervivencia individual con la supervivencia de la sociedad, el orden espontáneo de intereses coincide casi perfectamente con el bien común.

En cambio, en épocas más avanzadas y sofisticadas en que ya se ha superado la urgencia de la supervivencia, e incluso después de que la sociedad ha podido desarrollar un poder militar y económico importante en base al sacrificio en las guerras (época militar) y al esfuerzo y la disciplina productiva (época de acumulación productiva), la tendencia de los individuos es a dedicarse a disfrutar de los beneficios obtenidos y a abandonar la ética militar o económica rigurosa de los primeros tiempos. Así «este es el período del lujo y el disfrute, los cuales pasan a ser el bien

25 The Summary Cause for the Stability or Downfall of Human Societies, Volume 1 of The Philosophy of Politics, traducido por Denis Cleary y Terence Watson, Rosmini House, Durham, U.K., en Della sommaria cagione per la quale stanno o rovinano le umane societa, 1994, n. 56.

26 Ibid., n. 56. 
inmediato hacia el cual la gente tiende y de acuerdo al cual actúa.» ${ }^{27}$ Para Rosmini estas son las épocas de decadencia social en que el orden espontáneo de los intereses individuales, convertido en una competencia por la búsqueda autista del propio placer, evidentemente no lleva al bien de toda la sociedad e incluso destruye el verdadero bien de los individuos. Así en esos momentos la sociedad «está ciega para todo bien común del país y dedica su atención únicamente al bien individual, alrededor del cual gira brevemente antes de su colapso final.» ${ }^{28}$

Aquí vemos pues una diferencia clave de Rosmini con los iluministas escoceses. Para el roveretano el orden de intereses espontáneos no es un mecanismo completamente natural, sino que depende de la libertad y ésta, a su vez, de su adecuación mayor o menor a valores éticos objetivos. En tal sentido el orden espontáneo de intereses no siempre funciona bien ya que depende del grado de lucidez y virtud moral que posean los individuos y de los condicionamientos de la época en que viven para determinar su buena o mala orientación. Así, «la deficiencia e incapacidades de este estadio de la civilización consistirán, en mi opinión, en el hecho de que la gente haya arribado a condiciones en que el bien inmediato que están persiguiendo ya no es más la supervivencia o el prestigio de su país o incluso algún otro propósito accesorio al bien social sino que se mueven por la exclusiva búsqueda del bien individual.» 29

Además, los resultados buenos o malos del orden espontáneo varían también de acuerdo al lugar y al tipo de cultura de la sociedad de que se trate. En efecto, para Rosmini, los intereses económicos individuales de los habitantes de una nación no son fuerzas naturales que tienden siempre a favorecer a la sociedad en que están radicados, como piensa por ejemplo Adam Smith, cuando sostiene que la apertura comercial de un país no puede traer nunca su ruina porque los intereses económicos de ese país tenderán, como por propia fuerza gravitatoria, a favorecerse a sí mismos y haciéndolo, favorecerán también en consecuencia

\footnotetext{
27 Ibid., n. 58.

28 Ibid., n. 58.

29 Ibid., n. 60.
} 
al propio país. ${ }^{30}$ En opinión de Rosmini, en cambio, no toda liberación de los intereses económicos individuales es buena. Si bien la política económica debe tender siempre a buscar la libertad como ideal, no puede ignorarse que el grado de libertad que se permita dependerá del grado de capacidad para usar esa libertad, del nivel cultural y del nivel de ética que exista en cada país en particular. ${ }^{31}$ En este punto Rosmini, que es un admirador ferviente de Adam Smith — caso raro entre los filósofos católicos- sin embargo no acepta su tesis de la mano invisible. ${ }^{32} \mathrm{Me}-$ nos aún acepta la tesis de Mandeville de que los vicios privados se convierten en virtudes públicas.

Pero la falibilidad del orden espontáneo en el pensamiento de Rosmini radica en definitiva en un fundamento antropológico y ético más profundo que es el concepto de libertad, el cual, por lo demás, es muy diferente, en mi opinión, al concepto de libertad del liberalismo anglosajón. En efecto, para esta última tradición, el grado de libertad se mide, en general, por la mayor cantidad de posibilidades de acción externa por parte de un individuo.

30 «Every individual is continually exerting himself to find out the most advantageous employment for whatever capital he can command. It is his own advantage, indeed, and not that of society which he has in view. But the study of his own advantage naturally, or rather necessarily leads him to prefer that employment which is most advantageous to the society... therefore every individual naturally inclines to employ his capital in manner in which it is likely to afford the greatest support to domestic industry, and to give revenue and employment to the greatest number of people of his own country.» Adam Smith, op. cit, pp. 475-477.

31 «...l'azione governiale, che limita l'attività dei commerci e delle industrie vuol essere tanto maggiore quanto è maggiore in un popolo l'inerzia e l'ignoranza. Poichè non si può per mio credere consentire in questo all'opinione dello Smith e dei suoi seguaci: che l'interesse privato sia perfettamente istruito e non metta piede in fallo neppure considerato in una intera nazione, avvenendo certo il contrario in questo, secondo la rozzezza del popolo...In questo fatto adunque del commercio si vede l'applicazione di quanto sopra è ragionato intorno alla libertà, in cui debbe essere lasciato il popolo dal governo, che debbe essere tanta quanta è la scienza e la volontà che possiede di usarla.» Opere inedite di politica, edic. cit., pp. 139-140.

32 «Una volta si volevano spiegare gli avvenimenti tutti de' popoli mediante il libero arbitrio di alcuni pochi individui; ora che si è conosciuto che nell'andamento delle nazioni avvi qualche cosa d'independente dall'uomo, una mano invisibile che lo conduce, non si vuol più sapere di libero arbitrio: tutto avviene da sém per la natura delle cose. Tale è l'esagerazione in cui precipita la moderna scuola storica-fatalista!» La società ed il suo fine, edic. cit., p. 395, nota 5. 
Para Rosmini, en cambio, el grado de libertad tiene su última raíz en la capacidad de obrar con la menor cantidad de condicionamientos tanto externos como internos. En este sentido, no siempre la apertura de posibilidades externas significa un aumento de libertad. Por el contrario, una sociedad en que se de curso a un tipo de libertad que provoque una multiplicación exagerada de deseos y necesidades económicas puede generar, según Rosmini, expectativas inalcanzables para el sujeto y condicionarlo al extremo de adoptar cursos de acción negativos e incluso violentos que no sólo resultan un peligro para la libertad de los demás, sino que van directamente contra la libertad propia. ${ }^{33}$

Como consecuencia, si bien el orden espontáneo de los intereses económicos individuales es una dimensión fundamental de la vida social, el hecho de que no sea infalible y no siempre esté, por lo tanto, orientado al bien común, implica para el roveretano la necesidad de su orientación prudente desde las distintas instancias del gobierno de la sociedad política. De allí que, a pesar del enorme cuidado que para Rosmini debe tenerse al asignar funciones político-económicas al gobierno, y dejando en claro que éstas deberían ser predominantemente negativas, no obstante, parece haber en su pensamiento un papel más

33 «La suposición de que los seres humanos son siempre estimulados a ser más industriosos mediante la presión de necesidades crecientes es falsa. En ciertas circunstancias la presión sólo provoca el empobrecimiento y la extrema miseria en la gente que abandona lo que realmente necesita con el fin de satisfacer la urgencia irresistible de estas necesidades... Así las familias de campesinos y asalariados... hacen un esfuerzo excesivo... El trabajo excesivo, necesario para satisfacer sus necesidades, finalmente se vuelve opresivo y contrario a la naturaleza humana. Se instala la insatisfacción con el trabajo y la fuerza física se pierde... Si alguien en la casa se enferma o queda sin empleo, la reducción del ingreso intensifica la tensión... En otras palabras, cuanto más se cansa esta gente, más se tienta a abandonar el trabajo para buscar un medio que le de satisfacción inmediata sin tal opresión... ¿por qué los agricultores venden sus herramientas de trabajo? ¿por qué los que están cerca de la civilización venden sus tierras cultivadas? La respuesta es siempre: la necesidad de bebida, ropa fina, adornos inútiles y otras necesidades y deseos provocados en ellos... De este modo, nada puede ser más desastroso... que un sistema político que exija el aumento de las necesidades artificiales de los miembros de la sociedad pero no indica la cualidad o el límite de estas necesidades, o las clases en que estas necesidades artificiales puedan ser aumentadas con provecho o las circunstancias sociales que hagan deseable este aumento.» Ibid., pp. 329-339-334. 
importante para la política en materia económica que en la tradición liberal anglosajona.

En su doctrina de los equilibrios, el roveretano se refiere, por ejemplo, a la necesidad del «filósofo civil» y del gobernante de ponderar y calcular las fuerzas en juego en una sociedad e intervenir en los puntos conflictivos para lograr así una ordenación final. ${ }^{34}$ Esto último no lleva evidentemente a hablar de un racionalismo o constructivismo político o económico en Rosmini - forma de pensar que, como ya vimos, él rechaza explícita y enfáticamente en toda su obra- pero si parece dejar claro que no comparte la idea de la autorregulación completa de la economía. El orden espontáneo de los intereses individuales debe ser complementado siempre, para Rosmini, por la visión y orientación de individuos representantes del bien común de la sociedad: este es el papel de la alta política para auscultar la calidad de los distintos intereses - utilizando incluso el instrumento de lo que Rosmini llama «estadísticas político-morales»-con el fin de que las acciones del Estado atenúen lo más posible los efectos de las tendencias destructivas y fomenten las constructivas. ${ }^{35}$

Por lo demás, esto no significa para Rosmini que el Estado obligue a la virtud ni tampoco que pueda, con el pretexto de moralizar, violentar el derecho de nadie, pero tampoco puede ser el papel del Estado simplemente el de «abrir posibilidades». Para Rosmini la libertad política y económica está al servicio de

34 «...il filosofo civile debe osservare acutamente le leggi con che adoperano tutte le forze, le quali conferiscono a muovere le umane comunanze abbandonate a sè stesse, cioè lasciate operare secondo loro natura. Conciossacchè dall'aver conosciute queste leggi immutabili, egli trae l'arte di regolare il natural corso loro, acciocchè giammai non avvenga scompigliato e funesto, ma proceda ordinariamente a buoni effetti.» Opere inedite di politica, edic. cit., p. 177.

35 En este sentido Rosmini elogia el pensamiento de Alexander Hamilton y cita el siguiente pasaje de El Federalista para apoyar su tesis de que la política debe muchas veces corregir los deseos de los individuos y procurar orientarlos a sus verdaderos intereses: «Hablando en general, es verdad que la gente desea sólo el bien público. Sin embargo, están frecuentemente equivocados en cómo buscarlo... Cuando los deseos de la gente están en oposición a sus intereses reales, aquellos que son responsables de estos intereses tienen el deber de combatir el error del cual la gente es víctima...». La società ed il suo fine, edic. cit., n. 195. 
la libertad interior y en esto parece diferir del iluminismo escocés para el cual tal subordinación significaría el principio de un peligroso moralismo estatal. A juicio de Rosmini, en cambio, el Estado puede muy bien ejercer su acción desde el punto de vista del bien moral, sin por ello negar la libertad. En el caso más concreto de la economía, Rosmini cree que el papel del Estado es el de procurar que la libertad económica sea el medio y no el obstáculo para una mayor posibilidad de alcanzar la virtud moral, fin último de la sociedad. Por eso cree que la autoridad política no puede fomentar cualquier tipo de crecimiento económico que multiplique necesidades artificiales y genere una competencia ilimitada para satisfacerlas. De hecho para el roveretano tal tipo de política destruiría finalmente al sujeto y también a la economía.

\section{La crítica a la interpretación económica del derecho}

\section{a) El subjetivismo historicista}

Además de su crítica a la infalibilidad del orden espontáneo, Rosmini tiene también, a mi criterio, otra importante diferencia con el liberalismo escocés e inglés que es su crítica a su interpretación económica del derecho. En efecto, si bien nosotros hemos hecho referencia a la crítica que hace Rosmini del legalismo estatista de inspiración francesa y su preferencia evidente por la tradición jurídica británica como un tipo de derecho mucho más abierto a las necesidades de la economía, el roveretano no se adhiere tampoco por completo a esta última tradición. En efecto, si bien nuestro autor considera mucho más dañino para la sociedad al utilitarismo jurídico francés, no obstante, no por ello deja de ser un fuerte crítico del utilitarismo que ve también presente en la tradición jurídica inglesa.

En efecto, para Rosmini en tanto el racionalismo jurídico francés es un utilitarismo estatista en que las leyes son producto de una intervención artificial del Estado o de un grupo de hombres que legisla, el utilitarismo inglés y escocés suele ser un utilitarismo historicista y evolucionista muy vinculado a la filosofía 
económica escocesa e inglesa (Mandeville, Hume, Smith, Burke), ${ }^{36}$ al tradicionalismo francés y al historicismo alemán e italiano. En efecto, para este evolucionismo la ley positiva es el producto de la ley natural, pero entiende por «ley natural» el resultado de una interacción fáctica entre intereses aunque a lo largo de la historia. Según esta postura, las relaciones humanas a lo largo del tiempo van dejando como sedimento ciertas normas y reglas no escritas que son vistas como un «orden natural» por no haber sido elaboradas «artificialmente» por nadie en particular. En definitiva, las normas morales no serían sino «colecciones de hechos» que resultan de una interacción «natural» entre los hombres a lo largo del tiempo. ${ }^{37}$ Ahora bien —nos explica Rosmini- este orden jurídico y moral, recogido en las máximas y tradiciones históricas muchas veces sintetizadas por hombres sabios del pasado (aunque no creadas por ellos), no encuentra su justificación en el cálculo individual o social sino en una suerte de cálculo natural e histórico hecho por el sentido común de los hombres de innumerables generaciones en el pasado cuya justificación está demostrada exclusivamente por su misma perduración en el tiempo y que ningún cálculo artificial hecho hoy —individual o socialpuede reemplazar y mucho menos superar. ${ }^{38}$

${ }^{36}$ Este tipo de historicismo jurídico es retomado en el siglo XX por ejemplo por Hayek.

37 A este respecto veamos esta cita que Rosmini toma de Romagnosi: «Simigliante a questo concetto è appunto ciò che sembra dire il Romagnosi: "L'osservazione constante di simili fatti istruisce l'uomo a conoscere le sorgenti del bene e del male, a da questo deduce ciò che egli debba o fare od ommettere. Segnando separatamente queste azioni od ommissioni, necessariamente determinate dall'impero della natura su di lui, forma una collezione che serve di norma alla di lui potenza, onde procurare il meglio od evitare il peggio. Questa collezione cosí dedotta costituisce appunto la legge naturale che appellammo conseguente. Questa in sostanza forma la somma dei doveri determinati dai rapporti attivi, reali e necessari che passano fra la natura e l'uomo."» Storia comparativa e critica dei sistemi intorno al principio della morale, en Principi della scienza morale e Storia comparativa e critica dei sistemi intorno al principio della morale. A cura di Dante Morando, Opere edite e inedite, vol. XXI, Milano, Fratelli Bocca, Editori, 1941, p. 381.

38 «El hombre no debe ya hacer por sí mismo el cálculo del acuerdo entre el interés propio y el público: este cálculo ya ha sido hecho por hombres experimentados y está reducido a algunas máximas, cuyo mantenimiento es aquello que constituye la práctica de las virtudes especiales. A razón de ejemplo, es conocido ser una cosa 
Ahora bien, a juicio de Rosmini, el reemplazo del concepto de norma moral como el producto de un cálculo estatal por el de un cálculo histórico no cambia la esencia de esta concepción jurídica que sigue reduciendo el derecho a un conjunto de ventajas subjetivas, aunque consagradas a través de la fuerza de la historia. En efecto, para Rosmini el problema del movimiento del Law $\mathcal{E}$ Economics de su época representado por los economistas Melchiorre Gioia y Giandomenico Romagnosi, no es tanto su estatismo o su liberalismo, sino básicamente su fondo último utilitarista. Para éstos últimos -nos dice Rosmini- los derechos no eran otra cosa que «ventajas, beneficios y placeres de cualquier especie que la ley garantiza». ${ }^{39}$ Pero para Rosmini las leyes deben estar dotadas de "una bondad intrínseca», cuando no es así "ya no es la equidad ni la justicia la que me obliga a respetar las leyes sino sólo mi ventaja.» Así, si bien este historicismo jurídico parece opuesto al radicalismo reformista de otros utilitaristas, para Rosmini no es otra cosa, en definitiva, que una versión políticamente conservadora $^{40}$ de un esencialmente idéntico utilitarismo jurídico. ${ }^{41}$

útil tanto el bien privado como al público, que el hombre no se exceda en la comida y por eso se fijó la máxima "sed moderados en el comer": esta máxima llevada a la práctica constituye la virtud de la templanza. Dígase lo mismo de la fortaleza y de cada una de las virtudes. Cada una de estas virtudes en su origen tiene su origen en ningún otro lugar sino en una máxima, acerca de la cual la constante observación mostró la utilidad tanto publica como privada. Así, el hombre debe atenerse a estos juicios, máximas o virtudes ya establecidas $a b$ antico por el sentido común de los hombres y no querer abandonarse al propio juicio. De este modo la conducta humana se vuelve estable y la virtud conserva la constancia que le da tanta dignidad», ibid., p. 381.

39 Breve esposizione della filosofia di Melchiorre Gioja,Studi critici su Ugo Foscolo e Melchiorre Gioja. A cura di Rinaldo Orecchia, Padova, Cedam-Casa editrice Dott. Antonio Milani, 1976, p. 137, nota 2. Citado por Rosmini de la obra de Gioia Teoria civile e penale del divorzio, p. 6.

${ }^{40}$ Rosmini cita en tal sentido al filósofo Pablo Costa: «Nessuna cosa sarebbe più contraria al principio da noi stabilito, che il dare all'uomo l'arbitrio di crearsi le regole del giusto e dell'ingiusto nell'atto che sta per operare. Tali regole sono già state ritorvate coll' aiuto del detto principio dai filosofi morali, e ricevute dal consentimento de'popoli: a questo fine di bene pubblico si vuole, senza farne controversia, ubbidire.» Storia comparativa e critica dei sistemi intorno al principio della morale, edic. cit., p. 381.

41 Por lo demás, es bien conocida la coincidencia en la justificación utilitarista del derecho del conservador e historicista jurídico Edmund Burke con sus acérrimos enemigos, los benthamistas y radicals. Rosmini rechaza la reducción del derecho al 
Para el roveretano si bien la evolución espontánea de la sociedad va llegando a lo largo de la historia hasta cierto punto a soluciones para autorregularse, es decir, para alcanzar un conjunto de reglas que le sirven a sus fines, sin embargo, esto no implica que estas reglas coincidan necesariamente con la ética y el derecho. Esto es así para Rosmini porque en su opinión los valores éticos están fuera de la historia y no son mero producto de ella como ocurre en el tradicionalismo ético anglosajón. En efecto, para Rosmini, las doctrinas tradicionalistas que intentan reducir la acción moral al «sentido común» de una sociedad a lo largo de su historia, entendido como «creencias comunes...trasmitidas de generación en generación» incurren en el error de confundir los principios con algo que puede ser nada más que «el signo de esos principios, ${ }^{42}$ ya que el consenso social que recibe una norma a lo largo del tiempo es sólo un criterio «extrínseco y secundario de la certeza» ${ }^{43} y$, tomado por si sólo, se reduce a una mera suma de opiniones subjetivas que, en definitiva, remiten a la subjetividad individual como última medida del valor. De este modo, la conclusión final del roveretano con respecto a las teorías de la utilidad social como fundamento último del derecho será lapidaria:

Todos estos sistemas son subjetivistas, porque todos comienzan y terminan en el sujeto, todos se limitan a la excitación del sujeto que se satisface a sí mismo, que busca el bien para sí y nada más; no salen pues ni en sus principios ni en sus conclusiones de los límites del egoísmo... ${ }^{44}$

cálculo utilitario que es propio no sólo de los estatistas y radicales sino también en muchos casos de liberales y conservadores. Cfr. Edmund Burke, Reflections on the Revolution in France, Hackett, Indianapolis/Cambridge, 1987, p. 54: «The rights of men in governments are their advantages; and these are often in balances between differences of good, in compromises between good and evil, and sometimes between evil and evil. Political reason is a computing principle: adding, substracting, multiplying and dividing, morally not metaphysically or mathematically...».

42 Grande dizionario antologico del pensiero di Antonio Rosmini. A cura di Cirillo Bergamaschi, Roma, Centro Internazionale di Studi Rosminiani, Città Nuova, Edizioni Rosminiani, 2001, vol. 4, p. 318.

43 Ibid.

44 Storia comparativa e critica dei sistemi intorno al principio della morale, edic. cit., p. 167. 


\section{b) El callejón sin salida del utilitarismo}

Así, para Rosmini en la relación entre derecho y economía no se trata de reemplazar un utilitarismo estatista por un utilitarismo liberal sino en establecer la verdadera naturaleza del derecho mostrando su relación pero también su esencial diferencia con el principio de utilidad. Por lo demás, Rosmini no ve en el derecho algo ajeno al principio de utilidad. Por el contrario, para él «la palabra "derecho" designa una facultad que los seres humanos tienen para hacer o experimentar cualquier cosa útil.» ${ }^{45}$ Así, un aspecto del derecho tiene que ver con un beneficio subjetivo que puede obtener de su ejercicio una persona real o una persona jurídica. Si fuera de otro modo ¿qué podría significar un derecho si no beneficia al que lo posee? Sin embargo, si bien la utilidad que obtiene el sujeto del derecho es un elemento necesario de la naturaleza de este derecho, no obstante, no agota ni explica toda su naturaleza. Precisamente según Rosmini el utilitarismo consiste en la reducción del derecho a la utilidad en tanto ésta es sólo uno de sus elementos constitutivos. Pero, ¿adónde llegamos si explicamos el derecho sólo por el principio de utilidad?

En opinión de nuestro autor, las consecuencias de esta concepción conducen a callejones sin salida y a todo tipo de absurdos posibles. En efecto, si toda utilidad o necesidad subjetiva confiriera derecho, toda acción estaría justificada para un individuo en nombre de su supervivencia, su necesidad económica o simplemente su deseo de felicidad. Pero, ¿y si en lugar de poner el principio del derecho en la utilidad individual lo ponemos en la utilidad social?, ¿no es el derecho la obtención de utilidad individual pero siempre dentro de los límites de la utilidad de toda la sociedad?, ¿no se basa el derecho en buscar el propio beneficio pero sin alterar una coexistencia pacífica con los otros? Para Rosmini estos últimos argumentos no pueden fundar tampoco el derecho. En su opinión el intento de estos utilitaristas de introducir el principio de la sociabilidad o utilidad social en la teoría utilitarista

45 The Essence of Right, vol. 1 of The Philosophy of Right, traducido por Denis Cleary y Terence Watson, Rosmini House, Durham, U.K., en Filosofia del Diritto, ibid., 1993, n. 29. 
con el fin de evitar los problemas del utilitarismo individual no tiene sentido ya que, o deja al utilitarismo tal como está, o lo envuelve en una contradicción insoluble.

En efecto, introducido el principio de utilidad social hay sólo dos opciones: o se lo entiende como un puro medio para lograr la utilidad propia, con lo cual la consideración de los otros es pura ficción, o se lo entiende como un medio que usa el instinto o cálculo utilitario de cada individuo para lograr la utilidad de los demás, con lo cual «entre la utilidad propia y la de los otros antepondría la de los otros» cosa evidentemente absurda si se quiere mantener en pie el principio de utilidad como motivo último de las acciones de los individuos. ${ }^{46}$ Así, "una vez acordado que el hombre debe seguir siempre aquello que es útil, no hay razón alguna para que él deba anteponer jamás la utilidad de los demás a la suya propia o, en casos de conflicto, anteponer la utilidad social a la utilidad individual. Cuando el único valor de la utilidad social es lo que es útil para nosotros, la primera es un medio y la segunda un fin.» ${ }^{47}$

Evidentemente, Rosmini razona aquí de una manera irrefutable. Dado que para el utilitarismo «todo bien es relativo, todo se reduce a un cálculo del más o del menos, nada existe que deba ser mantenido por el hombre incondicionalmente: incluso el bien mismo de la sociedad entra en el cálculo.» ${ }^{48} \mathrm{La}$ única salida de este laberinto sería admitir la existencia de «una razón superior que me haga respetables y sagrados los bienes de los demás»: sólo así «yo no tengo necesidad de hacer ningún cálculo para saber si los debo o no respetar sino que simplemente los respeto sin sopesarlos de acuerdo a mi propia utilidad. ${ }^{49}$ Pero ¿cuál es esta razón superior que puede abrir la puerta de salida del laberinto utilitarista?

46 Ibid., p. 70.

47 Ibid., p. 71.

48 Storia comparativa e critica dei sistemi intorno al principio della morale, edic. cit., p. 378. Enseguida agrega una ilustración extremadamente gráfica: «si in un bacino io metto tutti i beni degl'altri individui, per quanto sieno, e nell'altro bacino getto il mio, tosto questo mio bene fa tracollare per me la bilancia, come se piombo fosse, e gli altri paglia: perocchè il mio bene individuale è mio, e gli altri non sono miei: e per me il mio bene val piu necessariamente, che gli altri non miei tutti insieme.» Ibid., p. 378.

49 SC, p. 378. Por lo demás, nos parece que en esta crítica entran tanto las teorías que reducen la moral a la utilidad de la sociedad actual como las que la reducen 


\section{c) La verdadera naturaleza del derecho}

La razón superior sobre la que se funda el derecho es para Rosmini la idea de justicia: «aplicando estas consideraciones al análisis de la legislación positiva me convencí de que la más simple, básica, y por lo tanto más noble idea es aquella de la justicia. Todos los intentos serios para razonar sobre la legislación positiva tienen que empezar aquí. Todo otro valor que posea la ley positiva es accidental, accesorio, derivativo; la esencia y perfección de las leyes consiste sólo en la justicia [...] Algunos ciertamente me querrán decir que la justicia es simplemente lo que es útil, y que no es más que el interés propio bien entendido[...] Pero la justicia es un principio, la utilidad es una consecuencia. Cuando la utilidad como consecuencia es considerada en su conexión con el principio de justicia, el pensamiento procede bien, cuando sólo la utilidad atrae la atención del espíritu, comienza a reinar la sofística en las mentes y la anarquía en la sociedad.» ${ }^{50}$

De este modo, el derecho contiene una utilidad pero no se limita a ella. Para Rosmini el derecho es una utilidad justa, es decir, una utilidad que no se justifica por sí misma sino en cuanto forma parte de un valor o bien objetivo más amplio presente en todo verdadero derecho. Pero ¿cuál es éste? Según Rosmini el bien objetivo, que es la base de todo derecho, es el bien que la razón puede descubrir como adecuado a la naturaleza humana de una persona no considerada subjetivamente, es decir en tanto fuente de satisfacción o felicidad subjetiva sino objetivamente, es decir, en tanto entendida y valorada por lo que es $-\mathrm{y}$ no por la utilidad que pueda traer - mediante la razón y la voluntad libre de otro ser humano o incluso del mismo que es sujeto de ese derecho. Rosmini llama a este bien objetivo el "verdadero bien humano.» Así, para Rosmini el derecho se apoya, en definitiva, en la existencia de una naturaleza humana que puede ser

a la utilidad de la sociedad a lo largo del tiempo. En efecto, como veremos en el capítulo referido a la dimensión social de la economía, para Rosmini, las doctrinas tradicionalistas que intentan fundar la moral sobre el «sentido común», entendido como «creencias comunes...trasmitidas de generación en generación».

50 The Essence of Right, vol. 1 de The Philosophy of Right, edic. cit., n. 8-9-10. 
conocida y respetada no por su utilidad sino por lo que es en sí misma.

De este modo, en este aspecto, Rosmini sigue claramente la tradición iusnaturalista del continente y acepta incluso la existencia de algunos derechos naturales absolutos de la constitución americana y francesa. De este modo, aunque se alimenta fuertemente del pensamiento británico, Rosmini no es un whigh ni un tory. Para él el derecho natural no es evolutivo en sus principios fundamentales sino sólo en sus formas de aplicación. Para Rosmini definitivamente no es un mero conjunto de reglas de juego que varían de acuerdo al orden espontáneo de la sociedad. La norma jurídica no es un mero dispositivo de orden social neutral con respecto a la moral. El derecho se apoya en la moral y por tanto, en valores objetivos.

\section{d) La verdadera relación con la economía}

Pero ¿qué hay entonces de la relación del derecho con la economía? ¿No se recae con esta posición en un absolutismo jurídico incompatible o, por lo menos, seriamente entorpecedor de la utilidad económica? En opinión de Rosmini, el hecho de fundar sólidamente el derecho en una idea objetiva de justicia hacia la naturaleza o bien objetivo del hombre no implica de ningún modo un racionalismo jurídico negador de la economía. Por el contrario, para el roveretano el racionalismo jurídico reduce el derecho a la ley positiva general, en cambio, en su opinión el derecho trasciende la generalidad de la ley y apunta a la justicia entendida como equidad. En efecto, según Rosmini «debemos distinguir entre la equidad de una ley y la generalidad de su concepción. La primera es una característica necesaria para que la ley sea justa, la segunda es un defecto que muchas veces hace que la ley sea injusta.» ${ }^{51}$ Así, la equidad no es una rasero que, al respetar el bien objetivo contenido en el derecho, elimina todas las particularidades y diferencias. Por el contrario, se trata precisamente del

51 Society and its Purpose, edic. cit., n. 229, nota 73. 
concepto más pleno de justicia que es el que toma en cuenta todo el bien objetivo posible contenido en quien es sujeto de derecho $\mathrm{y}$, haciendo esto, no lo reduce a un concepto o generalidad abstracta - como hace el racionalismo jurídico- sino que lo considera en toda la riqueza de su concretez.

Ahora bien, es precisamente a través de la justicia entendida como equidad - y no como mera ley general- donde no sólo es posible rescatar la esencia del derecho sino también todas las dimensiones que Rosmini llama «accidentales» pero que no por ser tales dejan de formar parte de las posibilidades de despliegue legítimas de un sujeto. Entre estas dimensiones accidentales de la justicia está justamente, la dimensión económica: «la utilidad verdadera y completa nace de la justicia aplicada rigurosamente [entiéndase la justicia como equidad y no como mero derecho positivo] hasta sus últimas consecuencias» ${ }^{52}$ De allí que para nuestro autor no haya mejor fomento de la economía que el que se sigue de un respeto lo más pleno posible de los derechos. ${ }^{53}$

Por lo demás esta concepción de la relación entre la economía y el derecho impregna la multitud de temas económicos particulares que Rosmini intentó explicar yendo más allá tanto del racionalismo estatista francés como del historicismo liberal anglo-escocés. Esa es la nota particular que caracteriza a las ideas

52 Della naturale Costituzione della società civile, Introduzione en Filosofia della Politica. A cura di Sergio Cotta, Milano, Rusconi, 1985, p. 669.

53 Tal es lo que ocurrió, según Rosmini, con el proceso histórico de la abolición de la esclavitud. Según el roveretano si bien el hombre pudo comprobar en muchos momentos de la historia la mayor utilidad económica del trabajo libre, sólo al ir descubriendo la dignidad de la naturaleza humana en la plenitud de sus derechos, se pudo descubrir también todas las posibilidades económicas que traía la salida de la esclavitud. De hecho, Rosmini critica a Sismondi quien para él se equivoca cuando quiere quitar el mérito de la abolición de la esclavitud al descubrimiento paulatino de la dignidad humana «atribuyéndoselo al interés de los señores». Este argumento utilitarista no es concluyente para el roveretano «ya que queda por explicar por qué los señores se dieron cuenta tan tarde de sus intereses y por qué todos los señores del mundo gentil, que ciertamente no estaban privados de avidez de obtener más beneficios, no vieron la utilidad del trabajo contratado y que según los principios de este autor es tan obvia. Él supone que solamente en tiempo de los bárbaros comenzó el trabajo de hombres libres en las tierras, pero también existieron en plena época de florecimiento del Imperio y de la republica romanas tal como atestigua Cicerón...» Della naturale Costituzione della società civile, edic. cit., nota 1, pp. 100-101. 
rosminianas del derecho de propiedad, de la política fiscal, la libertad de comercio y el derecho laboral, entre otras.

III

\section{CONCLUSIÓN}

Habiendo visto tanto las coincidencias como las diferencias entre Rosmini y el pensamiento liberal británico es posible, a mi juicio, sacar algunas breves conclusiones sobre su actualidad. En primer lugar, se podría decir que Rosmini tiene el mérito de haber sido uno de los pocos filósofos modernos de gran fuste no sólo en haberse interesado por la economía, sino en haber propuesto un diálogo entre ésta y las grandes discusiones de la filosofía moral y política. En segundo lugar, cabría decir que Rosmini también es uno de los pocos filósofos católicos de la modernidad - tal como ya lo hemos mencionado- en abrirse al pensamiento económico liberal, especialmente de raíz anglosajona, sin prejuicios sino con una gran predisposición a tomar todo lo bueno que en éste pudiera encontrar. De hecho, esto último lo llevó a adoptar una filosofía social y económica no muy lejana a la del liberalismo aunque, ciertamente, la de un liberalismo muy moderado.

Por lo demás, creo que un gran mérito de Rosmini ha sido también el de mostrar, desde un análisis con conocimiento del terreno y fuertemente involucrado con la lógica propia de los problemas -y no desde una postura extrínseca y moralista- el riesgo de que una concepción de la relación entre la economía y las instituciones, especialmente las jurídicas, resulte perjudicada por una asunción a-crítica de una determinada filosofía: tal es la advertencia que lanza Rosmini frente al utilitarismo, no sólo en su forma estatista, a la manera francesa, sino también en su forma liberal, a la manera británica. De este modo cabe pensar, entonces, si no sería bueno considerar algunos de los argumentos de este gran filósofo italiano cuando intentamos encontrar un marco de referencia para problemas cuya naturaleza requiere un fino equilibrio entre la perspectiva económica y la dimensión política o jurídica. En este sentido, el pensamiento de Rosmini puede resultar hoy de una enorme actualidad. 